\section{AB005. Assessing meaningful changes in disease activity as clinical trial clinical efficacy measures for cutaneous lupus erythematosus}

\author{
Srita Chakka ${ }^{1,2}$, Rebecca Krain ${ }^{1,2}$, Sarah Ahmed ${ }^{1,2}$, \\ Josef Symon S. Concha ${ }^{1,2}$, Rui Feng ${ }^{3}$, \\ Victoria P. Werth ${ }^{1,2}$ \\ ${ }^{1}$ Department of Dermatology, University of Pennsylvania, Philadelphia, \\ PA, USA; ${ }^{2}$ Corporal Michael J. Crescenz VAMC, Philadelphia, PA, \\ USA; ${ }^{3}$ Department of Biostatistics and Epidemiology, University of \\ Pennsylvania, Philadelphia, PA, USA \\ Correspondence to: Victoria P. Werth. Department of Dermatology, \\ Perelman Center for Advanced Medicine, Suite 1-330A, 3400 Civic \\ Center Boulevard, Philadelphia, PA 19104, USA. \\ Email: werth@pennmedicine.upenn.edu.
}

\begin{abstract}
To date, there are no approved treatments for cutaneous lupus erythematosus (CLE), a disease known to significantly burden a patient's quality of life (QoL). Clinical trials are important for the advancement of treatments and outcome measures of these trials should reflect clinically meaningful improvement in disease activity and its effect on QoL. Currently, clinical trials use an efficacy measure of $\geq 50 \%$ improvement in disease activity, defined by the Cutaneous Lupus Disease Area and Severity Index activity (CLASI-A) score, in patients with an initial CLASI-A score of $\geq 10$. However, the degree of improvement in disease activity needed to predict a meaningful impact on QoL has not been defined. This is a retrospective study of 126 patients enrolled in a longitudinal research database. Using a linear regression model, we calculated the percent change
\end{abstract}

and difference needed in CLASI-A to have an important impact on QoL, defined as a 9.38-point and a 7.37-point improvement in the Emotions and Symptoms subscales of Skindex-29, respectively. In patients with an initial CLASI-A score $\geq 8$, a decrease by $42.1 \%$ and a decrease by $31.0 \%$ in disease activity is associated with a meaningful impact in the Emotions and the Symptoms subscales, respectively. Using a CLASI-A score $\geq 8$ for trial entry allows for inclusion of patients with milder disease for whom improvement of CLASI-A by $\geq 50 \%$ has a meaningful impact on QoL, as determined by the Emotions and Symptoms subscales. In patients with moderate to severe initial disease, a respective decrease in activity by seven and five-points is not only clinically significant, but also has a meaningful impact on the Emotions and Symptoms subscales. Our findings establish appropriate trial endpoints by determining clinically significant change in disease activity associated with meaningful changes in patients' QoL.

Keywords: Cutaneous lupus erythematosus (CLE); clinical trials, quality of life (QoL); patient-reported outcomes; efficacy measures

doi: 10.21037/atm.2021.AB005

Open Access Statement: This is an Open Access article distributed in accordance with the Creative Commons Attribution-NonCommercial-NoDerivs 4.0 International License (CC BY-NC-ND 4.0), which permits the noncommercial replication and distribution of the article with the strict proviso that no changes or edits are made and the original work is properly cited (including links to both the formal publication through the relevant DOI and the license). See: https://creativecommons.org/licenses/by-nc-nd/4.0/.

Cite this abstract as: Chakka S, Krain R, Ahmed S, Concha JSS, Feng R, Werth VP. Assessing meaningful changes in disease activity as clinical trial clinical efficacy measures for cutaneous lupus erythematosus. Ann Transl Med 2021;9(5):AB005. doi: 10.21037/atm.2021.AB005 